\title{
Biotransformation of Ephedrine by Whole Cells of Cunnighamella elegans
}

\author{
Rosana Fernanda Hochmüller Fogaça ${ }^{1}$, Vanessa Zafaneli Bergamo², Amanda Zamboni', \\ Monique dos Reis ${ }^{1}$, Bruna Tassi Borile1, Maíra Kerpel dos Santos' ${ }^{1}$, \\ Adelina Mezzari ${ }^{3}$, Renata Pereira Limberger ${ }^{1}$
}

${ }^{1}$ Pharmaceutical Sciences Graduate Program, Federal University of Rio Grande do Sul-UFRGS, Porto Alegre, Brazil

${ }^{2}$ Agricultural and Environmental Microbiology Graduate Program, Federal University of Rio Grande do Sul-UFRGS, Porto Alegre, Brazil

${ }^{3}$ Faculty of Pharmacy, Analysis Department, Federal University of Rio Grande do Sul, Porto Alegre, Brazil

Email: rosana.fogaca@ufrgs.br

How to cite this paper: Fogaça, R.F.H., Bergamo, V.Z., Zamboni, A., dos Reis, M., Borile, B.T., dos Santos, M.K., Mezzari, A. and Limberger, R.P. (2017) Biotransformation of Ephedrine by Whole Cells of Cunnighamella elegans. Open Access Library Journal, 4: e3279.

http://dx.doi.org/10.4236/oalib.1103279

Received: December 6, 2016

Accepted: April 24, 2017

Published: April 27, 2017

Copyright $\odot 2017$ by authors and Open Access Library Inc.

This work is licensed under the Creative Commons Attribution International License (CC BY 4.0).

http://creativecommons.org/licenses/by/4.0/

\begin{abstract}
Ephedrine biotransformation reactions were performed using strain Cunninghamella elegans in order to obtain products similar to human metabolism products. The choice of strains used was based on previous literature review which identified the species Cunninghamella elegans as promising due to their phenotypic characteristics, such as expressing Oxidoreductases enzymes that are necessary for carrying out the oxidation and reduction reactions in the side chain of the molecule ephedrine, in addition to expressing monooxygenases enzymes cytochrome $\mathrm{P} 450$ superfamily, which in humans were found in the lipid bilayer of hepatocytes and were responsible for the hydroxylation process of substances. Therefore, it was performed experiments with strains of Cunninghamella elegans acquired by the mycology collection of the Federal University of Pernambuco, originating from different ecosystems. From screening step, it selected URM 4428 strain to present better profile biocatalytic to ephedrine. The results demonstrate the gradual formation of bioproducts in reversible character, and the reduction of bioproducts accompanied by the recovery of the substrate. To our knowledge, there are not previous scientific literature focusing the biotransformation of ephedrine by fungi, which demonstrates the uniqueness specific to our research and presents $C$. elegans, as a promising auxiliary tool in the exploration and understanding of the metabolism of amphetamine-type drugs in humans.
\end{abstract}

\section{Subject Areas}

Biotechnology 


\section{Keywords}

Biotransformation, Biocatalysis, Ephedrine, Cunninghamella elegans, Human Metabolism

\section{Introduction}

The approach called biotransformation or biocatalysis has been employed with varying purposes that include from the classical asymmetric producing biologically active substances or their intermediates, resolution of racemic mixtures, degradation of environmental pollutants, biosorption of heavy metals and biosurfactant production. As well as the aforsaid, the use of microbial models in biotransformation studies is also used to mimic human metabolism. The ability of microorganisms (MO), especially fungi, to mimic human metabolism has received much attention in recent decades. The use of microbial models for the study and obtaining products of human metabolism has been shown to be a very promising tool [1]-[6].

Increasingly, the use of these models has proved a complementary tool in the study of the pharmacokinetics of many drugs, emerging as a reliable and efficient alternative to rationalize studies involving experimental animals or even as an alternative to synthetic chemical in obtaining considerable amounts of a series of derivatives of drugs and medicines. However, biotransformation reactions and/or biocatalysis with the use of whole microorganism that advantages [7] include simplicity, low cost and facility of manipulation, possibility of screening for a large number of drugs and strains, reproducibility, possibility of working on a large scale, allowing isolation and structural identification, enzymatic machinery viable and recyclable. As well as this, it allows for coenzyme and cofactors high regio-, chemo- and enantio-selectivity, as well as making the work under mild and ecological conditions more acceptable when compared with classical chemical techniques.

Among the available microbial models, filamentous fungi can be considered the most promising, besides providing a reasonable amount of biomass (biocatalyst) in a relatively short time. They are eukaryotic and therefore, closer to the human system of mammals than bacteria [8].

The species Cunninghamella elegans Lendner 1907 is the most important among Zygomycetes distributed worldwide and widely used in science. The separation of the species occurs, among other criteria-the optimal temperature for the growth of culture. The Cunninghamella are sensitive to variations related to the constitution of the medium, temperature and humidity, which can result in differences in growing isolates of the same origin. However, the biotechnological potential of $C$. elegans can be considered for their presence in studies that relate to the metabolism of recalcitrant compounds, biological models for metabolizing drugs by fungi, DNA extraction in large scale, and microbiological production processes chitin and chitosan [9] [10] [11] [12]. 
The choice of strains used was based on previous literature review, which identified the species $C$. elegans as promising due to their phenotypic characteristics, such as expressing oxidoreductases enzymes that are necessary for carrying out the oxidation and reduction reactions in the side chain of the ephedrine molecule. There are also present in this organism monooxygenases enzymes for cytochrome P450 superfamily, which in humans are found in the lipid bilayer of hepatocytes and are responsible for the hydroxylation process of substances.

This study aimed to perform biotransformation reactions using integrity cells cultures of microorganisms as a catalyst and supplemented with ephedrine as exogenous substrate. Furthermore, we obtained biotransformation products from the use of C. elegans and optimization of biocatalysis systems and developing the biotransformation reactions.

\section{Material and Methods}

\subsection{Collection and Growth Optimization of Microorganisms}

Strains Cunninghamella elegans (URM 2450, URM 1591, URM 2136, URM 2497, URM 2084, URM 4428, UM 3172, URM 4271, URM 6175, URM 5017, URM 3173, URM 4473, URM 4017, URM 4177, URM 5656, URM 5780, URM 6017) belonging to University Recife Mycology of the Federal University of Pernambuco in the form of culture tubes containing potato dextrose agar.

Afterwards, spore cultures were removed with handles inoculation on laminar flow hood and placed in cryovials, containing $1 \mathrm{~mL}$ TSB-broth Glycerol 10\% and stored at $-20^{\circ} \mathrm{C}$ for the maintenance of enzymatic ability of microorganisms. In order to optimization and growth of microorganisms and acquisition of appropriate biomass for biotransformation reactions, the cryovials containing spores were thawed slowly and subcultured into tubes containing Agar Sabouraud Himedia (Composition: Dextrose $40.000 \mathrm{~g} / \mathrm{L}$, mycological, peptone $10.000 \mathrm{~g} / \mathrm{L}$ and agar $15.000 \mathrm{~g} / \mathrm{L}$ ) and incubated for 4 days at $28^{\circ} \mathrm{C}$.

\subsection{Determination of Reaction Conditions}

For the acquire biomass were tested malt, Sabouraud and potato sucrose broth at temperatures of $28^{\circ} \mathrm{C}$ and $36^{\circ} \mathrm{C}$ and $\mathrm{pH} 5.0,6.0$ and 7.0, during three days in rotary shaker (shaker) at $140 \mathrm{rpm}$. There were no significant differences in the formation of biomass between different broths at temperatures of $28^{\circ} \mathrm{C}$ and $\mathrm{pH}$ 6.0 approximately, and thus, suitable conditions for the acquisition of biomass chosen for the reactions. Considering that income equality between the three types of broths, it was defined using the broth potato sucrose by economic efficiency issues and operational research, being the most cost-effective and aimed at future production on a larger scale.

\subsection{Growth and Optimization of Microorganisms to Perform Screening}

For determine what time should be made to supplement ephedrine in reaction 
broths, aimed at realization of biocatalysis reactions, it is to performed curve for the elucidation of the microorganism growth phases. The method used was the optical density. By this method, a light beam crosses a cell suspension and reducing the amount of transmitted light, resulting from diffraction, it is considered a measure of cell density [13].

The growth of $C$. elegans URM 4428 was performed in microplate with reference to the method recommended by CLSI [14]. First, the fungus was grown at $28^{\circ} \mathrm{C}$ in tubes containing Sabouraud dextrose agar for $72 \mathrm{~h}$. Then, cell suspensions were prepared in RPMI medium (L-glutamine without sodium bicarbonate) containing $0.4 \times 10^{4}$ to $5 \times 10^{4} \mathrm{CFU} / \mathrm{mL}$. The suspension containing the microorganisms was placed in the microplate in sextuplicates, followed by first reading spectrophotometer, which was considered as zero time; also added to the microplate only RPMI medium without the presence of microorganisms in order to demonstrate that the increase in absorbance readings of suspensions would be associated with the growth of microorganisms. Immediately after the first reading, the microplate with the suspensions and broths was placed in an oven at $28^{\circ} \mathrm{C}$. In the time zero tests were performed on days $3,6,9,12,24,36$, 48, 60 and 72 hat wavelengths $570 \mathrm{~nm}$ and $690 \mathrm{~nm}$ in Spectra Max M2 spectrophotometer.

\subsection{Determination of Standard Curve Ephedrine}

For determine the ephedrine concentrations to be used as a substrate in the biotransformation reactions by the enzymes present in microorganisms, calibration curves were done at concentrations of $600,800,1000,1200,1400$ and 1600 $\mu \mathrm{g} / \mathrm{mL}$, thus obtaining the linearity $\left(\mathrm{R}^{2}=0.9979\right)$. For the substrate preparation used $0.8 \mathrm{~g}$ of ephedrine in $50 \mathrm{~mL}$ of distilled water in a volumetric flask $(\mathrm{C}=1.6$ $\mu \mathrm{g} / \mathrm{mL}$ ). The biotransformation reactions were performed after the filtering of the means containing microorganisms. Furthermore, it was added $3 \mathrm{~g}$ biomass phosphate buffer solution with $\mathrm{pH}$ 5.0, 6.0 and 7.0, respectively, performed at temperatures of $28^{\circ} \mathrm{C}$ and $36^{\circ} \mathrm{C}$. These reactions were supplemented with aqueous ephedrine work solutions $0.16 \%$. The resulting broth filtrate was also supplemented with $0.16 \%$ ephedrine.

Reactions were carried out with the same microorganisms that have not undergone filtering or whole broth containing the microorganisms and supplemented with aqueous ephedrine work solution. The best result was one where there was no separation between microorganism and broth. The experiments were performed at $28^{\circ} \mathrm{C}$ temperature and $36^{\circ} \mathrm{C}$ and $\mathrm{pH}$ 5.0, 6.0 and 7.0. Thus, it was considered that these are the right conditions, and it was decided to use the temperature of $36^{\circ} \mathrm{C}$. Such a choice happened given that temperature approaching the human physiological temperature.

\subsection{Monitoring of Biotransformation Reactions}

For the monitoring of biotransformation reactions it was conducted screening tests lasting 10 days, counting the first $24 \mathrm{~h}$ after the day that supplementation 
was performed. For the screening steps every $24 \mathrm{~h}$, aliquots were removed $7 \mathrm{~mL}$, raised to $\mathrm{pH} 10$, with $\mathrm{NaOH} 0.01 \mathrm{M}$ (for the extraction of ephedrine free base), added $3 \mathrm{~mL}$ of ethyl acetate. The tubes were slowly stirred to avoid the formation of emulsion, centrifuged at $4000 \mathrm{rpm}$ for $30 \mathrm{~min}$ for complete separation of the organic and aqueous phases. $2 \mathrm{~mL}$ of the organic phase were removed with the aid of micropipette, placed in vials and taken to a water bath at $70^{\circ} \mathrm{C}$ to make the concentration. After being concentrated, products were reconstituted with 200 $\mu \mathrm{L}$ of methanol to follow the reactions using analysis by Thin Layer Chromatography (TLC), phase Gas Chromatography with Ionization Flame Detector (GC/ FID) and confirmation of Gas Chromatography Mass Detector (GC/MS), following methods previously reported and validated by our research group [15] [16] [17].

\subsection{Chromatographic Analysis}

The effectiveness of biocatalytic reactions was determined by the application and analysis by two chromatographic methods: The Thin Layer Chromatography (TLC) in the screening step and Gas Chromatography (GC) and (CG-MS) to confirmation. The monitoring performed TLC using aluminum plates chromatographic Alugram ${ }^{\otimes}$ Xtra SIL G/UV 254 in the size of $20 \mathrm{~cm} \times 20 \mathrm{~cm}$ and a thickness of $0.20 \mathrm{~mm}$, employing silica gel 60GF as stationary phase. The mobile phase used was methanol: ammonia (100:0.5). The migration distance was 10 $\mathrm{cm}$. For detection, plates were dried in an oven at a temperature of $100^{\circ} \mathrm{C}$ for 10 min and visualized under UV light with $254 \mathrm{~nm}$. As chromogenic reagents it was used Nihidrina and Dragendorf. The monitoring of biotransformation reactions was performed by GC/FID coupled with flame ionization detector(CG 2010 Shimadzu) for the qualitative analysis and confirmation in the chromatograph to gas CG 5975C coupled to a detector 7890A mass (Agilent Technologies, CA, USA), from Toxicology Laboratory of the Faculty of Pharmacy at UFRGS (LABTOXICO) [17]. In the analysis by GC/FID was used as the nitrogen carrier gas with a flow rate of $1.0 \mathrm{ml} / \mathrm{min}$ and synthetic air and hydrogen as auxiliary gas to the flame. The injector was maintained at a temperature of $220^{\circ} \mathrm{C}$ and operated in 1:50 split mode. The chromatographic analyzes were performed on a Durabond-DB5 column $(30 \times 0.25 \mathrm{~mm} \times 0.25 \mu)$. The oven temperature was programmed starting at $80^{\circ} \mathrm{C}(3 \mathrm{~min})$ with a ramp of $50^{\circ} \mathrm{C} / \mathrm{min}$ to $280^{\circ} \mathrm{C}(3 \mathrm{~min})$ resulting in $10 \mathrm{~min}$ as total time of analysis.

In the analysis by GC/MS was used as carrier gas helium ultrapure with a flow rate of $1.0 \mathrm{ml} / \mathrm{min}$. The injector was maintained at a temperature of $220^{\circ} \mathrm{C}$ and operated in 1:50 split mode. The chromatographic analyzes were performed on an Agilent-DB5-MS column $(30 \times 0.25 \mathrm{~mm} \times 0.25 \mu)$. The temperatures of the interface, the ion source and the quadrupole were maintained at $280^{\circ} \mathrm{C}, 230^{\circ} \mathrm{C}$ and $150^{\circ} \mathrm{C}$, respectively. The column temperatures were the same as used in GC/FID. The mass detector was operated at $70 \mathrm{ev}$ electron impact system and analyzes were performed in SCAN mode range from 50 to $450 \mathrm{~m} / \mathrm{z}$. The total analysis time was $10 \mathrm{~min}$. 


\section{Results and Discussion}

The biotransformations reactions of ephedrine mediated by $C$. elegans followed the flowchart shown in Figure 1.

The choice of strains used was based on previous literature review which identified the species $C$. elegans as promising due to their phenotypic characteristics, such as expressing oxidoreductases enzymes that were necessary for carrying out the oxidation and reduction reactions in the side chain of the ephedrine molecule. Also present in this organism is the monooxygenases enzyme cytochrome P450 superfamily, which in humans is found in the lipid bilayer of hepatocytes and is responsible for the hydroxylation process of substances [6] [18].

For optimizing the growth of microorganisms, strains were tested on different culture media, temperature and $\mathrm{pH}$ (Table 1). The extraction of ephedrine and products was performed by raising the $\mathrm{pH}$ from 6.0 to 10 , all the aliquots with 0.01 mole sodium hydroxide and fixed with 0.1 molar hydrochloric acid as needed. The optimum conditions for growth of microorganisms were $\mathrm{pH} 6.0$ for potato sucrose broth and temperature of $28^{\circ} \mathrm{C}$ rotating incubator for three days (Table 1).

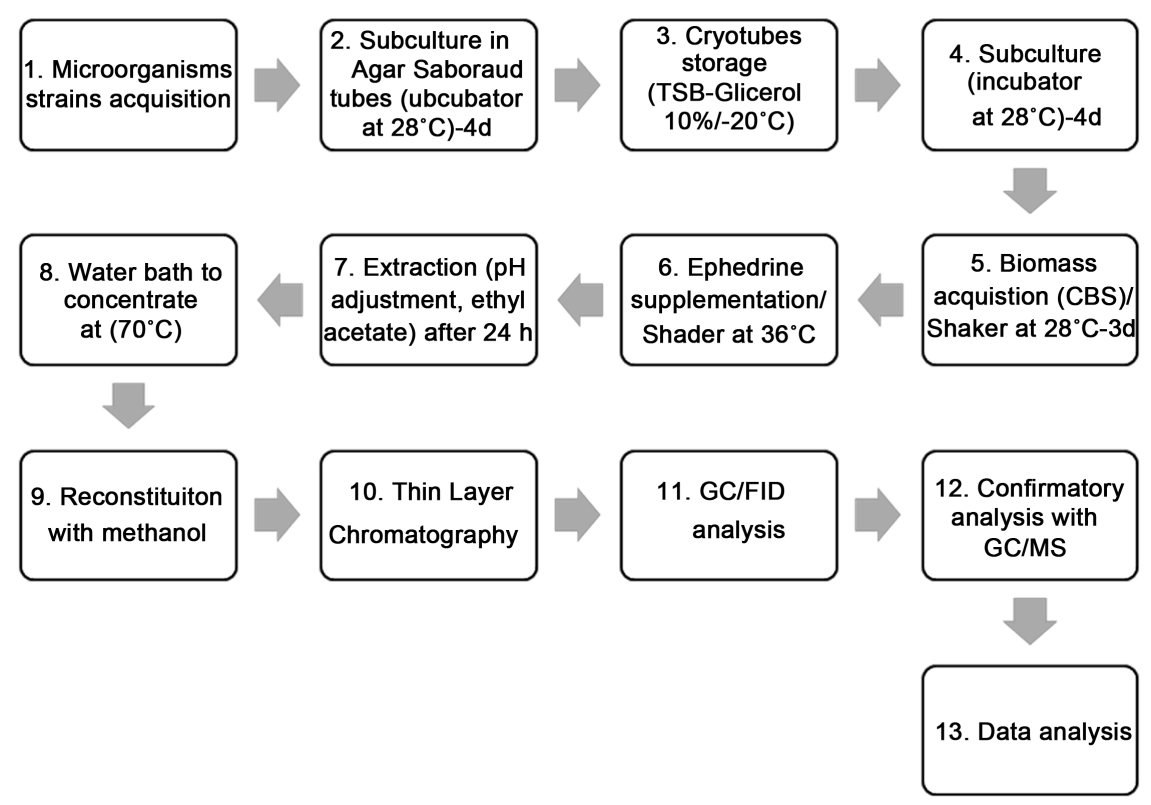

Figure 1. Flowchart of the experiment phases.

Table 1. Growth and optimization of microorganisms to perform screnning.

\begin{tabular}{ccccc}
\hline & \multicolumn{3}{c}{ Incubation conditions } & \\
\cline { 2 - 4 } Microorganism & $\begin{array}{c}\text { Culture } \\
\text { medium }\end{array}$ & $\begin{array}{c}\text { Temperature } \\
\left({ }^{\circ} \mathrm{C}\right)\end{array}$ & $\begin{array}{c}\text { Time } \\
(\text { days })\end{array}$ & Biomass (g) \\
\hline Cunninghamella elegans URM 1591 & PSB & $26-28$ & 3 & \pm 20 \\
Cunninghamella elegans URM 5780 & PSB & $26-28$ & 3 & \pm 20 \\
Cunninghamella elegans URM 4271 & PSB & $26-28$ & 3 & \pm 20 \\
Cunninghamella elegans URM 4428 & PSB & $26-28$ & 3 & \pm 20 \\
\hline
\end{tabular}

PSB $=$ Potato sucrose broth. 
On the conditions tested, the strain of $C$. elegans 4428 demonstrated most promising biocatalytic potential and was selected for the development of this work. To determine what time should be made to supplement ephedrine in reaction broths, aiming at realization of biocatalysis reactions, was performed and growth curve for the determination of the microorganism growth phases. The method employed was the optical density and the results are the optimum point to supplement the broths shown in Table 2.

According to Figure 2, the latency phase, or lag phase, during which the microorganism adapts to the new physical-chemical conditions of the environment in order to grow, occurs in the first $12 \mathrm{~h}$ of onset of growth in both growth me-

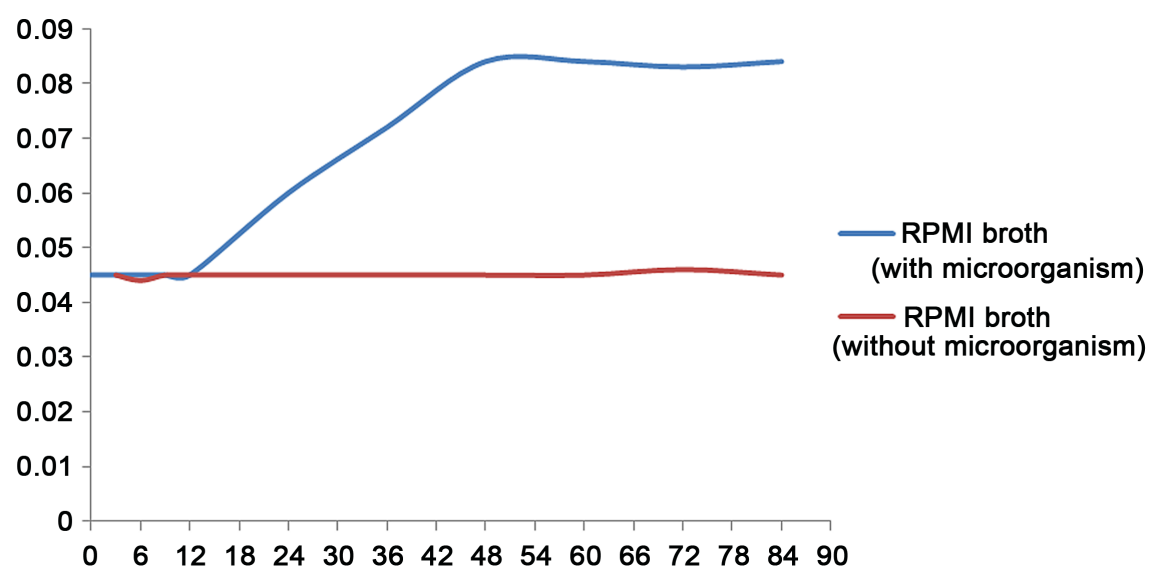

Figure 2. Growth curve of Cunninghamella elegans 4428 strains in RPMI medium (with and without microorganism). The latency phase, or lag phase, occurs between 0 and 12 hours, from 12 hours to 48 hours, the growth phase occurs and the stationary phase occurs after 48 hours.

Table 2. Time versus absorbance Cunninghamella elegans (RPMI).

\begin{tabular}{ccc}
\hline Time/h & RPMI (with microorganism) & RPMI (without microorganism) \\
\hline 0 & 0.045 & 0.045 \\
3 & 0.045 & 0.044 \\
6 & 0.045 & 0.045 \\
9 & 0.045 & 0.045 \\
12 & 0.045 & 0.045 \\
24 & 0.060 & 0.045 \\
36 & 0.072 & 0.045 \\
48 & 0.084 & 0.045 \\
60 & 0.084 & 0.046 \\
72 & 0.083 & 0.045 \\
84 & 0.084 & \\
\hline
\end{tabular}

RPMI $=$ Roswell Park Memorial Institute (RPMI) 1640 medium. 
dia, and is followed by the growth stage progressive period which the growth is accelerated and metabolic activity is high. This cell population is perceptibly increased in accordance with the time chart, and occurs between 12 and $48 \mathrm{~h}$. It is followed by the deceleration phase and stationary phase, in which there is depletion of substrates. At this stage, the cells cease their growth, given that the maximum capacity reached in their development [13]. From a screening step, in this research, experiments were conducted in optimal conditions for growth, acquisition of biomass and biocatalysis reaction. Opted for the use of microorganism growth $72 \mathrm{~h}$ to effect the supplementation with ephedrine work solution, since in this phase, there is greater enzyme stability, thus avoiding the transient formation of products.

Fixed the ideal conditions of the experiment, the process was developed with the cultivation of microorganisms of the cells in an oven for four days, and subsequent process of acquiring biomass and studies of growth phases. Verification of the stability of all the elements present in the biotransformation reaction process that has relevance to discard the possibility of abiotic degradation of the substrate and exudation of the assembly of these components. To the end, experiments were conducted in which we evaluated the product formation in the presence and absence of biocatalytic agent (fungi), as well as the presence or absence of substrate. The groups evaluated in this study step were described below. 1) white Medium (MB): bottle containing only broth without microorganism and without substrate (reaction to check exudation products broth); 2) Total White Medium (MTBR): vial containing broth, microorganism, but without the substrate (reactions for checking exudation products MO); 3) Part ephedrine (Mef): $25 \mathrm{~mL}$ of the aqueous solution of ephedrine $1600 \mu \mathrm{g} / \mathrm{mL}$ was added to the medium containing broth but no microorganism (reaction substrate for the stability check); 4) Total Medium (TM): vial for performing the complete reaction that contains all elements for biotransformation, or broth, microorganism and $25 \mathrm{~mL}$ of sat. aqueous ephedrine $1600 \mu \mathrm{g} / \mathrm{mL}$ (MT). After supplementation, the flasks were placed back on the rotary shaker and the temperature was raised to $36^{\circ} \mathrm{C}$, the speed of $140 \mathrm{rpm} .7 \mathrm{~mL}$ aliquots were taken which were raised to $\mathrm{pH}$ 10 with $\mathrm{NaOH} 0.01 \mathrm{M}$ and adding $3 \mathrm{~mL}$ of ethyl acetate, stirred slowly bottles were centrifuged at $4000 \mathrm{rpm}$ for $30 \mathrm{~min}$ to complete separation of the organic phase and aqueous phase. $2 \mathrm{~mL}$ of organic phase was removed and placed in vials and taken to a water bath at $70^{\circ} \mathrm{C}$ to make the concentration. After being concentrated, products were reconstituted with $200 \mu \mathrm{L}$ of methanol.

Ephedrine showed good resolution and its chromatographic retention time was $6.16 \mathrm{~min}$ in GC/MS (Figure 3) and $7.08 \mathrm{~min}$ in GC/FID.

Various biotransformation products were obtained as verified by analysis on GC/FID (Figure 4) and confirmed by GC/MS. Among the products obtained, three were selected (P1, P2 and P3) (Figure 5). Products 4, 5 and 6 are shown in Figure 6.

Through the data obtained, the formation of products was observed to follow a same pattern behavior bioproducts from the obtained; three showed higher 


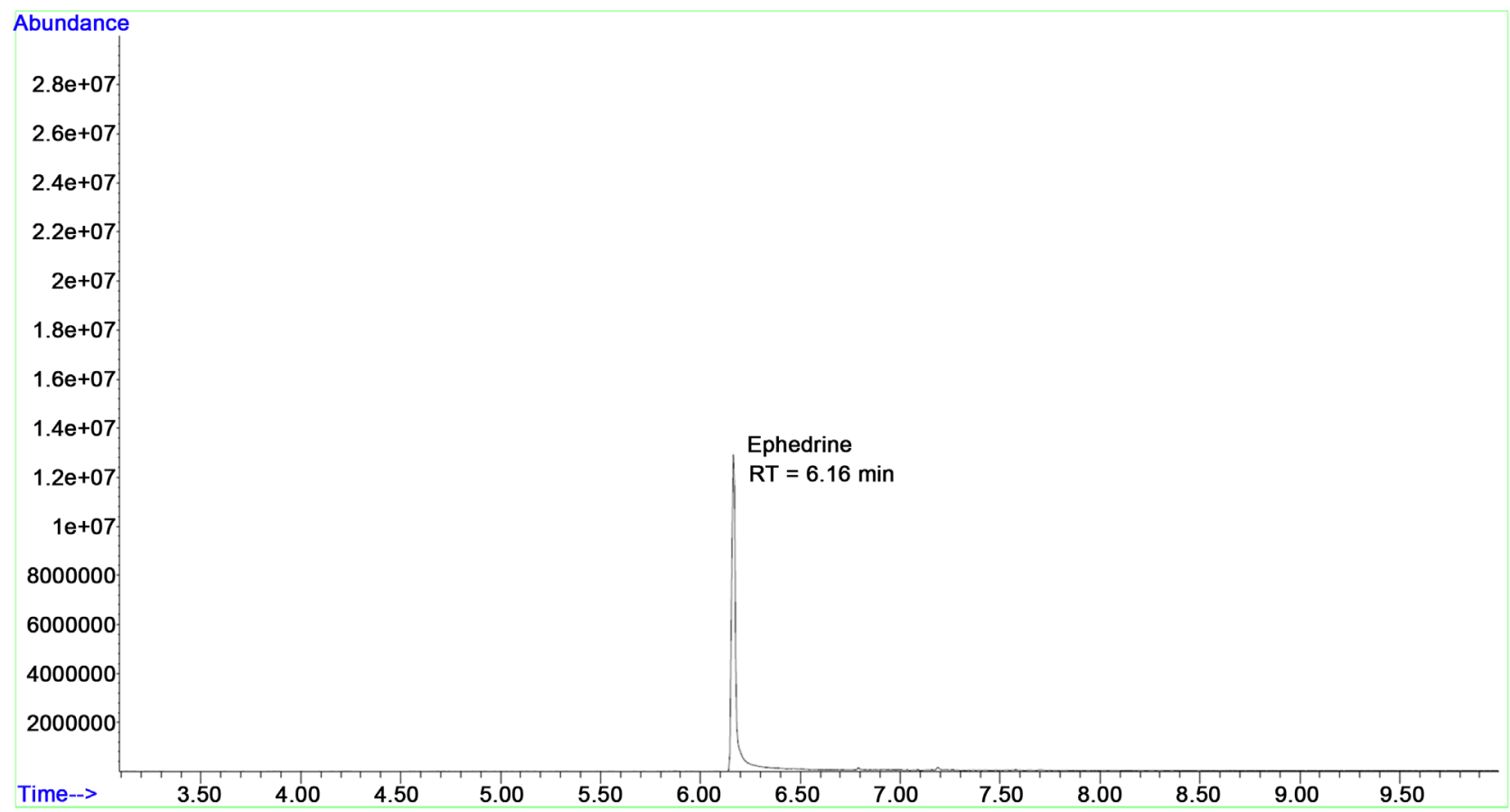

Figure 3. GC/MS chromatogram of ephedrine.

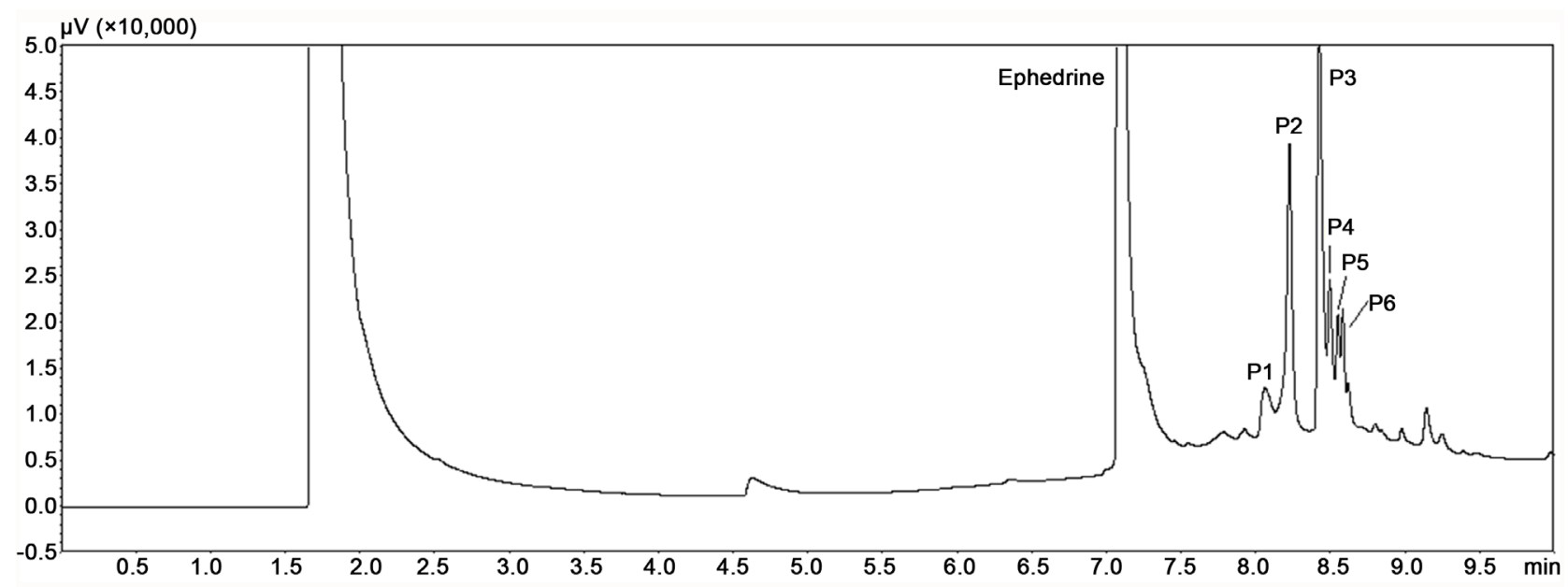

Figure 4. GC/FID chromatogram of the Ephedrine reaction with microorganisms at 48 hours.

yield and were then selected for monitoring of the biocatalytic reactions, and the points in 2 days, 5 days and 9 days, as shown in Figure 7. During the first two days of biocatalysis reactions, it was observed the constant increase of the biotransformation products $\mathrm{P} 1, \mathrm{P} 2$ and $\mathrm{P} 3$, and decreased concentration of ephedrine. This behavior was repeated in the fifth and ninth days for the three products, the product 2 (P2), the only detected on the seventh day. It was observed that after having increased the reduction products thereof, with a proportional recovery of the substrate, which suggested that the reaction had reversible characters.

For better understanding of the reactions, aspects regarding the degradation resulting from extractive processes, transformations, stability problems and 


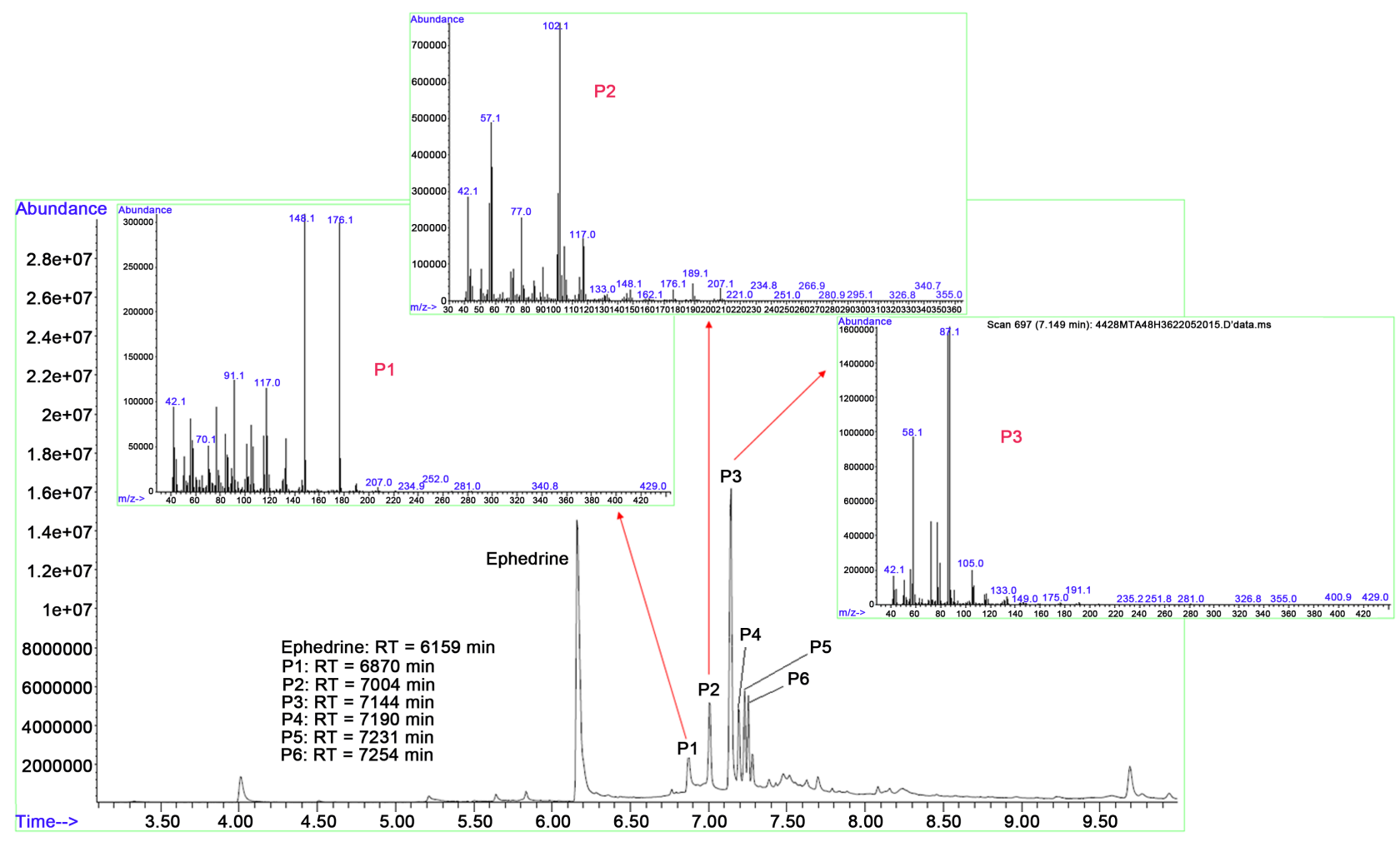

Figure 5. GC/MS chromatogram of ephedrine (48 h of reaction) and its biotransformation products' mass spectrum.

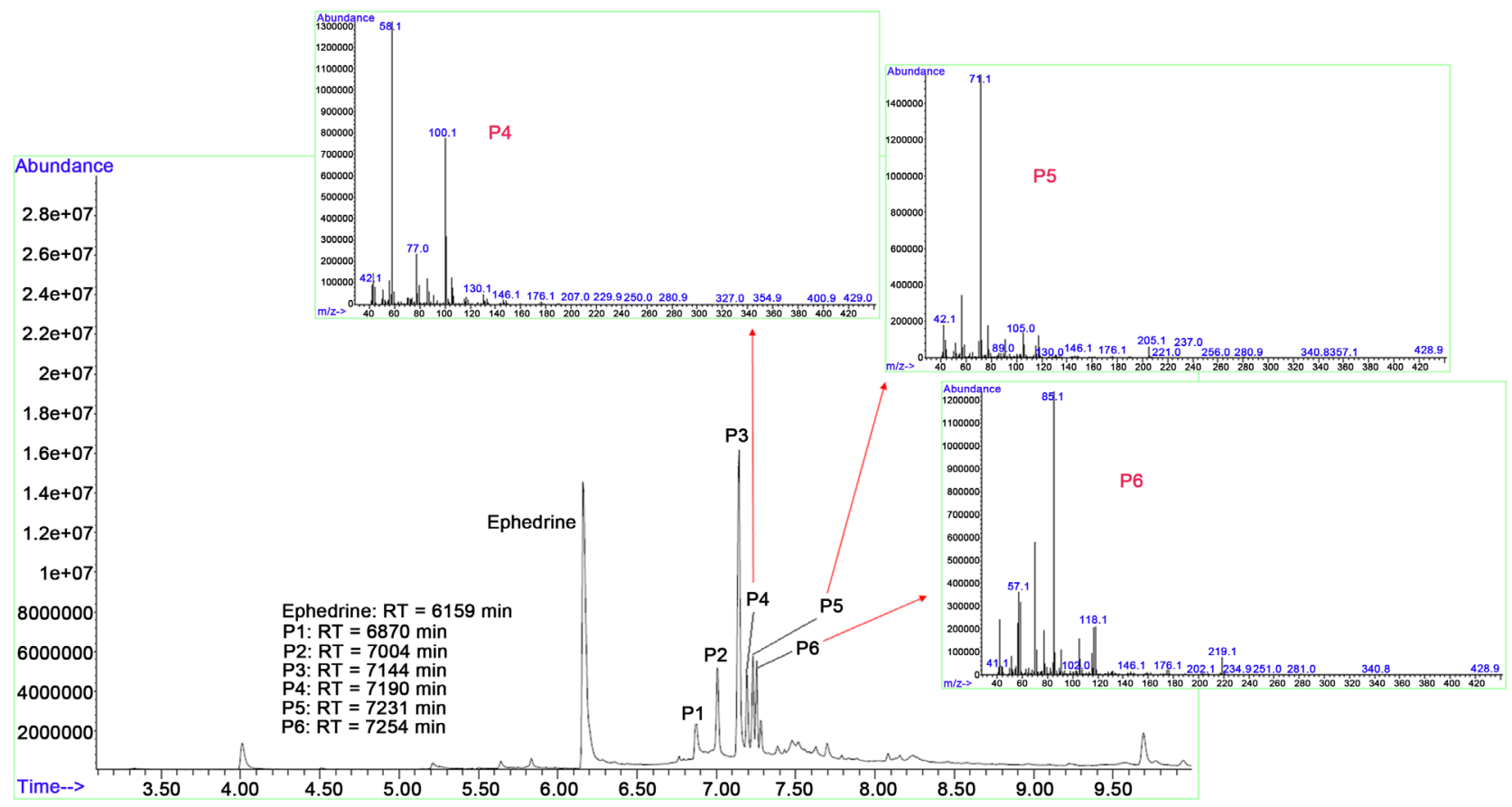

Figure 6. GC/MS chromatogram of ephedrine (48 h of reaction) and its biotransformation products' mass spectrum.

possible presence of contamination of products, were conducted in several experiments, named control experiments, which were switched to the presence of the substrate, the biocatalytic agent and the culture medium alone and in combination. The results of these tests carefully evaluated, did not afford the detection 


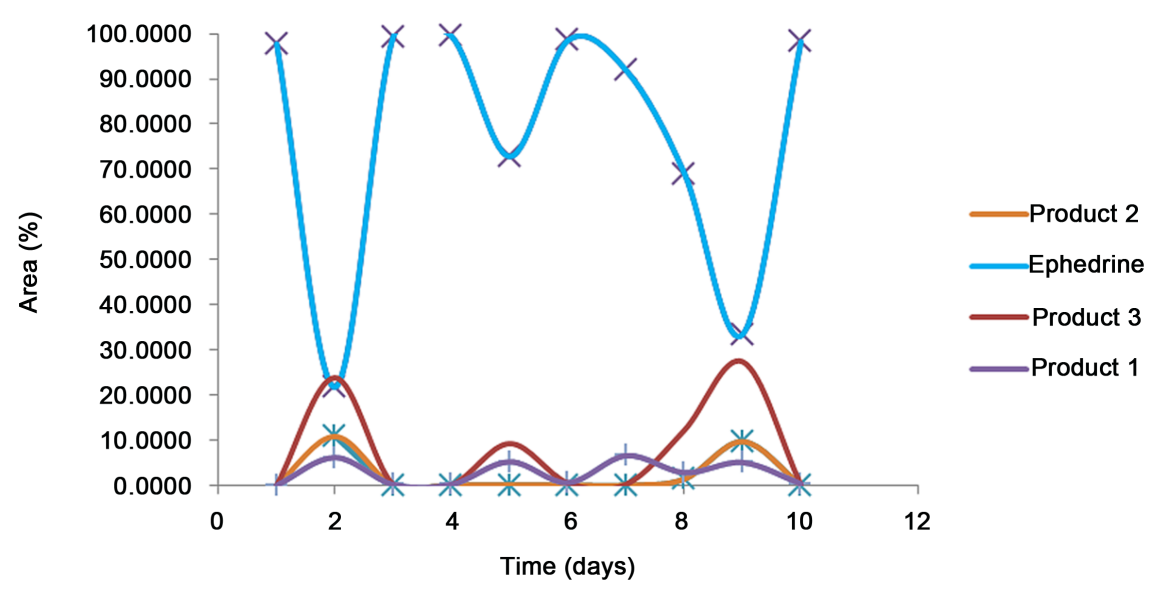

Figure 7. Kinetic of 10 days of Ephedrine biotransformation reaction with Cunninghamella elegans URM 4428.

of substances obtained as the product of the biotransformation reactions, thus confirming the biotransform products obtained during the reactions were mediated by $C$. elegans biocatalysis.

The study of ephedrine biotransformation kinetics in hours for the experiment conducted for $72 \mathrm{~h}$, confirms the default behavior of a reversible reaction when it has been observed over a period of 10 days. In fact, it is a reversible reaction in which the maximum formation of products P2, P3 and P1 occurs in $12 \mathrm{~h}$ and $15 \mathrm{~h}$ respectively. All products have reached their lowest point in 24, 54 and $72 \mathrm{~h}$, in which proportional increase of the concentration of ephedrine (substrate) is observed.

To confirm the reversible character reactions, more detailed tests were conducted. To the reaction, kinetics studies were conducted for 3 days of experiments $(72 \mathrm{~h})$ for removal of aliquots in triplicates every $3 \mathrm{~h}$ by repeating the same procedures used when the extraction range and concentration of the aliquots were $24 \mathrm{~h}$ for 10 days. The results are shown in Figure 8.

A careful review of scientific literature to date, has not found references to the biotransformation of ephedrine yeast, especially $C$. elegans, which demonstrates the uniqueness specific to our research. The data in the literature regarding the biotransformation ephedrine and other amphetamines in different animal species is incipient, limiting the understanding of the pharmacological activity and potential toxicity of this class of substances. Neither was it highlighted in the various ephedrine biotransformation studies in rats and mice i.e. the species most commonly used in toxicological studies.

The existing differences in metabolism between species must be taken into consideration and it is noteworthy that some biotransformation products can provide equivalent toxicity or greater to the drug administered and should be evaluated in isolation. Small animals such as mice, biotransforms compounds generally at a faster rate than that observed when the experiment occurs in larger animals such as humans. This is in line with differences in overall metabolic rate. As Timbrell (2004), there are qualitative and quantitative differences between species with regard to the biotransformation of amphetamine (Figure 9). Similar 


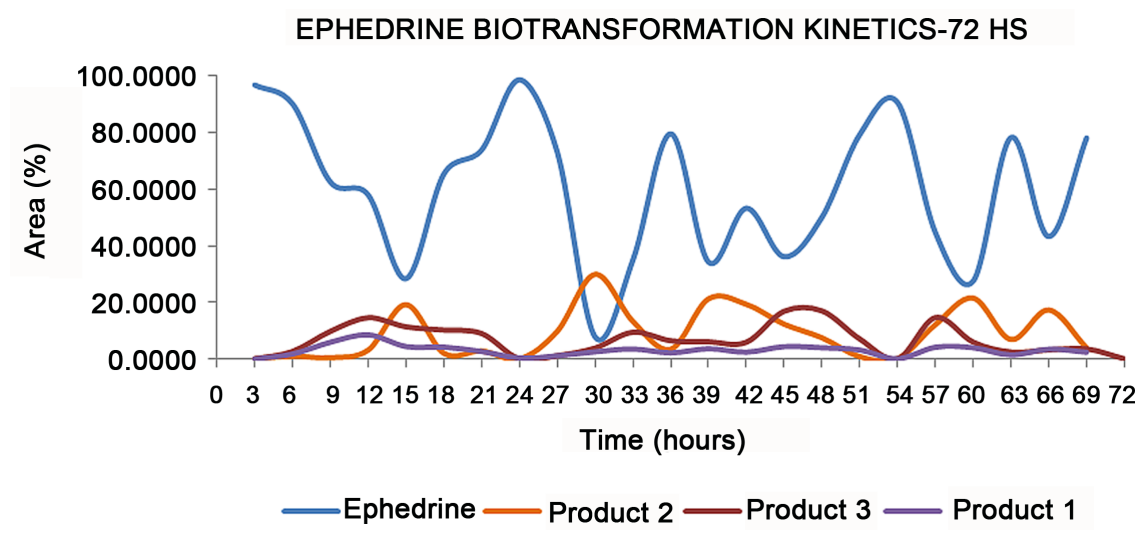

Figure 8. Kinetic of 72 hours of Ephedrine biotransformation reaction with Cunninghamella elegans URM 4428.

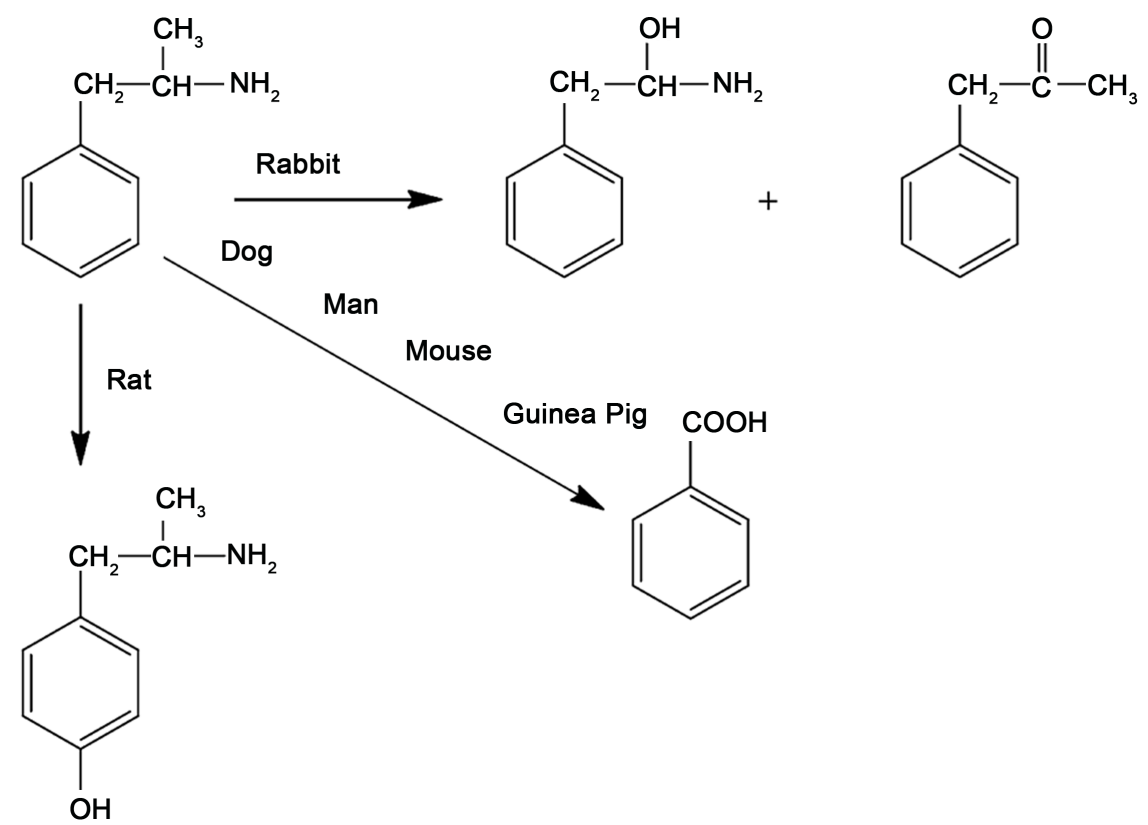

Figure 9. Differences between species with regard to the biotransformation of ampheta$\min$.

results were not found for ephedrine, but we suggested that one should be careful in extrapolating results obtained in tests on laboratory animals to assess the risk of use by humans.

Several factors may affect the biotransformation of drugs. These factors may be chemical and/or biological, also considering toxic effects. Chemical factors that need to be taken into consideration are the lipophilicity, size, structure, $\mathrm{pK}$, ionization and chirality of the molecule. Already biological factors present in relation to the species, breed, sex, genetic factors, disease and pathology [19].

Also under consideration were not only the large variations in susceptibility between species, but also the various factors that may be involved in any given species. In this sense, there is the genetic constitution of specific body as a relevant factor involved in metabolizing substances. Code can be added to the importance of other internal factors, such as age and certain features of their body systems. 
Among the external factors, dose and used associations can influence the biotransformation; the way is the diet management and exposure to other foreign compounds, which can result in deviations of biotransformation patterns and hence the detectability in biological samples and toxicity profiles.

According Timbrell (2004), amphetamine is biotransformed in rabits for phenylacetone (Figure 9). This mechanism probably involves the oxidation of the carbon atom, to obtain a carbinolamine, which can rearrange to the ketone with loss of ammonia. Alternatively, it is possible that the reaction has continued through phenylacetoneneoxome, isolated as a product, which has several possible routes to their training. Ranging from the hydrolyzed to phenylacetone. Also $\mathrm{N}$-hydroxylation amphetamine is liable to occur and may lead to phenylacetone as a product of biotransformation. This example illustrates the possibility of a varied number of alternative routes for obtaining amphetamines biotransformation products; many of them have not yet described in the literature.

In this context, the use of microorganism demonstrates to be an important promising tool for better understanding of biotransformation processes of this class of substances and has the advantage of optimizing the rationalization and the use of experimental animals such as rats, rabbits and guinea pigs, showing higher ethical commitment and avoiding lengthy deliberative processes by the ethics committees of the entities where these experiments are performed. It also highlights the fact that the microorganisms, mostly achieve rapid growth and development of their phenotypic expressions, which provides the speed of obtaining products by biotransformation large-scale process (Figure 10).

The biotransformation reactions mediated Cunninghamelas shown to be a promising tool in the study of ephedrine biotransformation and other amphetamine derivatives, and demonstrated the applicability of the biotransformation

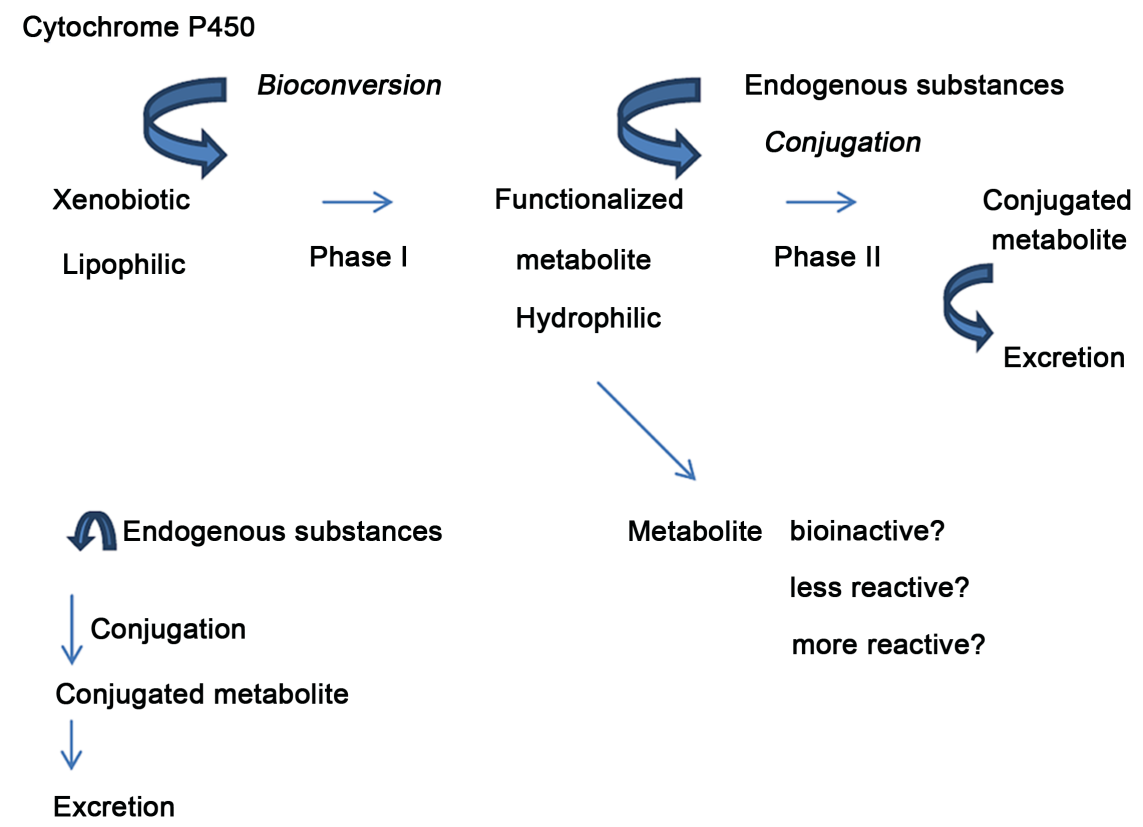

Figure 10. Cytochrome P450 metabolism in microorganisms and humans. 
to study metabolism in humans. In the reactions obtained in this study, it was found the presence of several biotransformation products through the optimal conditions established in the experiment, in reversible character. The reproducibility of the product was confirmed by repeating the experiments, always accompanied by other reactions without microorganisms and without substrate, to ensure biocatalysis. From the mass spectra biocatalytic, one profile was obtained with formation of six majority products for $48 \mathrm{~h}$, and this reaction had reversibility, observing the recovery of the substrate in time of lowering products. To complete elucidation of the structure of the products obtained in future, work steps are conducted on a larger scale experiment; isolation of products are evaluated by Nuclear Magnetic Ressonance (NMR); Infra-red and High-resolution Magnetic Ressonance (HRMNS) is performing parallel tests between MO and animal tests and clinical trials.

\section{Acknowledgements}

The authors would like to thank CNPq (National Council of Technological and Scientific Development) and FAPERGS (Research Support Foundation of the State of Rio Grande do Sul).

\section{References}

[1] Clark, A.M., Hufford, C.D., Gupta, R.C., Puri, R.K. and McChesney, J.D. (1984) Microbial Transformation of Primaquine by Candida tropicalis. Applied and Environmental Microbiology, 47, 537-539.

[2] Clark, A.M. and Hufford, C.D. (1991) Use of Microorganisms for the Study of Drug Metabolism: An Update. Medicinal Research Reviews, 11, 473-501. https://doi.org/10.1002/med.2610110503

[3] Abourashed, E.A., Clark, A.M. and Hufford, C.D. (1999) Microbial Models of Mammalian Metabolism of Xenobiotics: An Updated Review. Current Medicinal Chemistry, 6, 359-374.

[4] Asha, S. and Vidyavathi, M. (2009) Cunninghamella-A Microbial Model for Drug Metabolism Studies-A Review.'Biotechnology Advances, 27, 116-29. https://doi.org/10.1016/j.biotechadv.2008.07.005

[5] Borges, K.B., Borges, W.S., Duran-Patron, R., Pupo, M.T., Bonato, O.S. and Collado, I.G. (2009) Stereoselective Biotransformations Using Fungi as Biocatalysts. Tetrahedron: Asymmetry, 20, 385-397. https://doi.org/10.1016/j.tetasy.2009.02.009

[6] Amadio, J., Casey, E. and Murphy, C.D. (2013) Filamentous Fungal Biofilm for Production of Human Drug Metabolites. Applied Microbiology and Biotechnology, 97, 5955-5963. https://doi.org/10.1007/s00253-013-4833-x

[7] Wong, C.H. and Whitesides, G.M. (1994) Enzymes in Synthetic Organic Chemistry. In: Pergamon, Ed., Tetrahedron Organic Chemistry Series, Oxford.

[8] Saxena, S. (2009) Fungal Biotransformation of Cannabinoids: Potential for New Effective Drugs. Current Opinion in Drug Discovery \& Development, 12, 305-312.

[9] Franco, L.O. (2005) Aspectos bioquímicos e fisiológicos do acúmulo de polifosfato inorgâmico por Cunninghamella elegans. UFPE, Tese de Doutorado (Biologia de Fungos), 108f.

[10] Berger, L.R.R., Félix, F.F., Borges, T.K.S., Malheiros, S.M.M. and Stamford, N.P. 
(2009) Cultivo de Cunningamella elegans (UCP 542) em meio BD. IX Jornada de Ensino, Pesquisa e Extensão JEPEX 2009. VI Semana Nacional de Ciência e Tecnologia. Recife, 19 a 23 de outubro.

[11] Félix, F.F., Berger, L.R.R., Silveira, A.C.G.A. and Stamford, N.P. (2009) Perfil de crescimento de Cunningamella elegans (UCP 542) em meio Saboraud. IX Jornada de Ensino, Pesquisa e Extensão JEPEX 2009. VI Semana Nacional de Ciência e Tecnologia. Recife, 19 a 23 de outubro.

[12] Lee, J.O.H., Chun, E. and Keum, Y.S. (2014) Biotransformation of Isoflavones by Aspergillus niger and Cunninghamella elegans. Journal of the Korean Society for Applied Biological Chemistry, 57, 523-527. https://doi.org/10.1007/s13765-014-4145-6

[13] Azevedo, E.E. (2004) Fungos: Uma introdução à biologia, bioquímica e biotecnologia. Educs, Caxias do Sul.

[14] CLSI-Clinical and Laboratory Standards Institute (2008) Reference Method for Broth Dilution Antifungal Susceptibility Testing of Filamentous Fungi.

[15] Andrade, A.S., Schmitt, G., Rossato, L.G., Russowsky, D. and Limberger, R.P. (2009) Gas Chromatographic Method for Analysis of p-Synephrine in Citrus aurantium L. Products. Chromatographia, 69, 225-229.

https://doi.org/10.1365/s10337-009-0991-5

[16] Viviane, C.S. (2007) Análise de efedrinas e anfetamina em urina empregando SPE e SPME por CG/EM/EM. Dissertação (Mestrado em Ciências Farmacêuticas)Universidade Federal do Rio Grande do Sul. Renata Pereira Limberger, Orientador.

[17] Schmitt, G.C., Arbo, M.D., Lorensi, A.L., Maciel, E.S., Krahn, C.L., Mariotti, K.C., Dallegrave, E., Leal, M.B. and Limberger, R.P. (2012) Toxicological Effects of a Mixture Used in Weight Loss Products: $p$-Synephrine Associated with Ephedrine, Salicin, and Caffeine. International Journal of Toxicology, 31, 184-191. https://doi.org/10.1177/1091581811435708

[18] Zhang, D.L., Evans, F.E., Freeman, J.P., Yang, Y.F., Deck, J. and Cerniglia, C.E. (1996) Formation of Mammalian Metabolites of Cyclobenzaprine by the Fungus, Cunninghamella elegans. Chemico-Biological Interactions, 102, 79-92. https://doi.org/10.1016/S0009-2797(96)03736-2

[19] Timbrell, J. (2004) Principles of Biochemical Toxicoligy. 3rd Edition. Taylos \& Francis, London.

Submit or recommend next manuscript to OALib Journal and we will provide best service for you:

- Publication frequency: Monthly

- 9 subject areas of science, technology and medicine

- Fair and rigorous peer-review system

- Fast publication process

- Article promotion in various social networking sites (LinkedIn, Facebook, Twitter, etc.)

- Maximum dissemination of your research work

Submit Your Paper Online: Click Here to Submit

Or Contact service@oalib.com 